\title{
South American species of Paragordius Camerano, 1897 (Gordiida, Nematomorpha), with redescription of Paragordius minusculus and a description of a new species
}

\author{
Fernanda Zanca ${ }^{1,2^{*}}$ and Cristina de Villalobos 1,3 \\ ${ }^{1}$ Facultad de Ciencias Naturales y Museo, UNLP, Paseo del Bosque S/N, La Plata, ${ }^{2}$ Consejo Nacional de Investigaciones Científicas y \\ Técnicas, CONICET, ${ }^{3}$ Comisión de Investigaciones Científicas, CIC; Argentina
}

\begin{abstract}
Paragordius is a genus of Gordiida with a worldwide distribution. but with a scarce specific diversity. Sixteen species of the genus Paragordius have been described so far. In many cases, as with the other genera of Gordiida, the original descriptions of the species are insufficient due to the limitations of the techniques employed. In this work the holotypes of $P$. minusculus and $P$. esavianus are redescribed by scanning electron microscopy (SEM), a new species of Paragordius is described. the distribution for $P$. esavianus and $P$. varius is enlarged and a new host record of $P$. esavianus is presented.
\end{abstract}

\section{Key words}

Paragordius. Gordiida, Nematomorpha. SEM

\section{Introduction}

The Gordiida or hairworms have a worldwide distribution, inhabiting mainly tropical and subtropical areas. At present 19 genera of freshwater nematomorphs are known (Zanca and Schmidt-Rhaesa 2006)

In spite of being one of those genera among Gordiida which have the widest worldwide distribution (together with Gordius. Gordionus and Chordodes), Paragordius has a scarce specific diversity. Sixteen species of the genus Paragordius have been described so far. Nine species are from Africa: P. areolatus Linstow, 1906; P. cinctus Linstow, 1906; P. dartevellei Sciacchitano, 1958; P. flavescens Linstow, 1906; P. laurae Sciacchitano. 1958; P. marlieri Sciacchitano. 1958; P. mulungensis Sciacchitano, 1958; P. somaliensis Sciacchitano, 1962; P. tanganikensis Sciacchitano. 1958 (Linstow 1906; Sciacchitano 1958. 1962); two are from Europe: P. stylosus (Linstow, 1883); P. tricuspidatus (Dufour, 1828) (see SchmidtRhaesa 1997); two are from Asia: P. emeryi (Camerano, 1895) (Camerano 1895); P. stylosus Linstow. 1883 (Linstow 1883. Camerano 1915); one is from North America: P. varius (Leidy, 1851) (see Schmidt-Rhaesa et al. 2003); two are from Central America: P. diversolobatus Heinze. 1935; P. varius (Heinze 1935. Schmidt-Rhaesa and Menzel 2005); and four species are known for South America: P. esavianus (Carvalho 1942. de Villalobos et al. 2000); P. flavescens Linstow. 1906
(Linstow 1906); P. minusculus Carvalho. 1944 (Carvalho 1944) and P. varius (see Miralles and de Villalobos 1993. de Villalobos et al. 2000).

The genus Paragordius is characterized by a trilobed posterior end in females and two long and narrow lobes in males. The cuticle varies between different species being able to form transverse irregular cords with knoblike structures on top (Schmidt-Rhaesa et al. 2003) or with poorly defined, shallow areoles (de Villalobos et al. 2001). Areoles are cuticular structures in compartments which may be flat. polygonal or more elevated and elaborated (Schmidt-Rhaesa 2002).

In many cases. as with the other Gordiida genera, the original descriptions of the species are insufficient due to the limitations of the techniques employed. In this work the holotypes of $P$. minusculus and $P$. esavianus are redescribed by scanning electron microscope (SEM). a new species of Paragordius is described the distribution for $P$. esaviamus and $P$ v varius is enlarged and a new host record of P. esavianus is presented.

\section{Materials and methods}

We examined the holotypes of Paragordius minusculus (MNRJ container 118. in vial without accession number) and Paragordius esavianus (MNRJ container 118, in vial without ac- 
cession number) deposited in Museu Nacional of Rio de Janeiro. Brazil. Also. we investigated specimens of $P$. esavianus, $P$. varius and Paragordius sp. housed in the Museu Nacional of Rio de Janeiro. Brazil (MNRJ), the Museo de Ciencias Naturales de La Plata, Argentina (MLP). Fundacion Miguel Lillio. Instituto de Zoología. Tucumán. Argentina (IML) and Facultad de Tecnología y Ciencias Aplicadas. Universidad Nacional de Catamarca (FTyCA). All the preserved specimens were fixed in ethanol.

Body measurements were made with outstretched worms using a ruler. Diameters were measured under dissecting microscope using a calliper ruler.

In order to preserve the holotype of $P$. minusculus and $P$. esavianus we removed a tangential section of the middle region of the body with a razorblade. The posterior ends of the above mentioned specimens were only investigated under light and stereomicroscope.

Specimens were dehydrated in an increasing ethanol series, critical point-dried. mounted on bronze blocks and gold sputter-coated. Observations were performed using a JEOL JSM 6360 LV scanning electron microscope. All preparations. i.e. SEM stubs, are stored together with the preserved specimens in the respective museums.

\section{Results}

\section{Paragordius minusculus Carvalho, 1944 (Fig. 1)}

Description: Light brown body, $70 \mathrm{~mm}$ long and $0.5 \mathrm{~mm}$ in diameter. Anterior end rounded with dark collar behind the white tip. The mouth opening terminal. The posterior end with two long and narrow lobes with postcloacal spines on the ventral and inner side. The cloacal opening oval.

The cuticle of midbody (Fig. 1A-C) presents a velvet-like aspect as it is mostly covered by digit-like cuticular projections, like bristles, with blunt apex. These projections are different in height (1.3-3.2 $\mu \mathrm{m})$ and are not uniformly distributed. In spite of the cuticle surface being fully covered with bristles in some sectors remnants of areole borders can be observed (Fig. 1C).

Holotype: Male.

Type locality: Viscosa. Minas Gerais, Brazil.

Host: Unknown.

Material investigated: Holotype (MNRJ vial 118, without accession number) (stereomicroscope, posterior end; SEM midbody).

Distribution: Viscosa, Minas Gerais, Brazil.

Remarks: Carvalho (1944), when describing the cuticle of
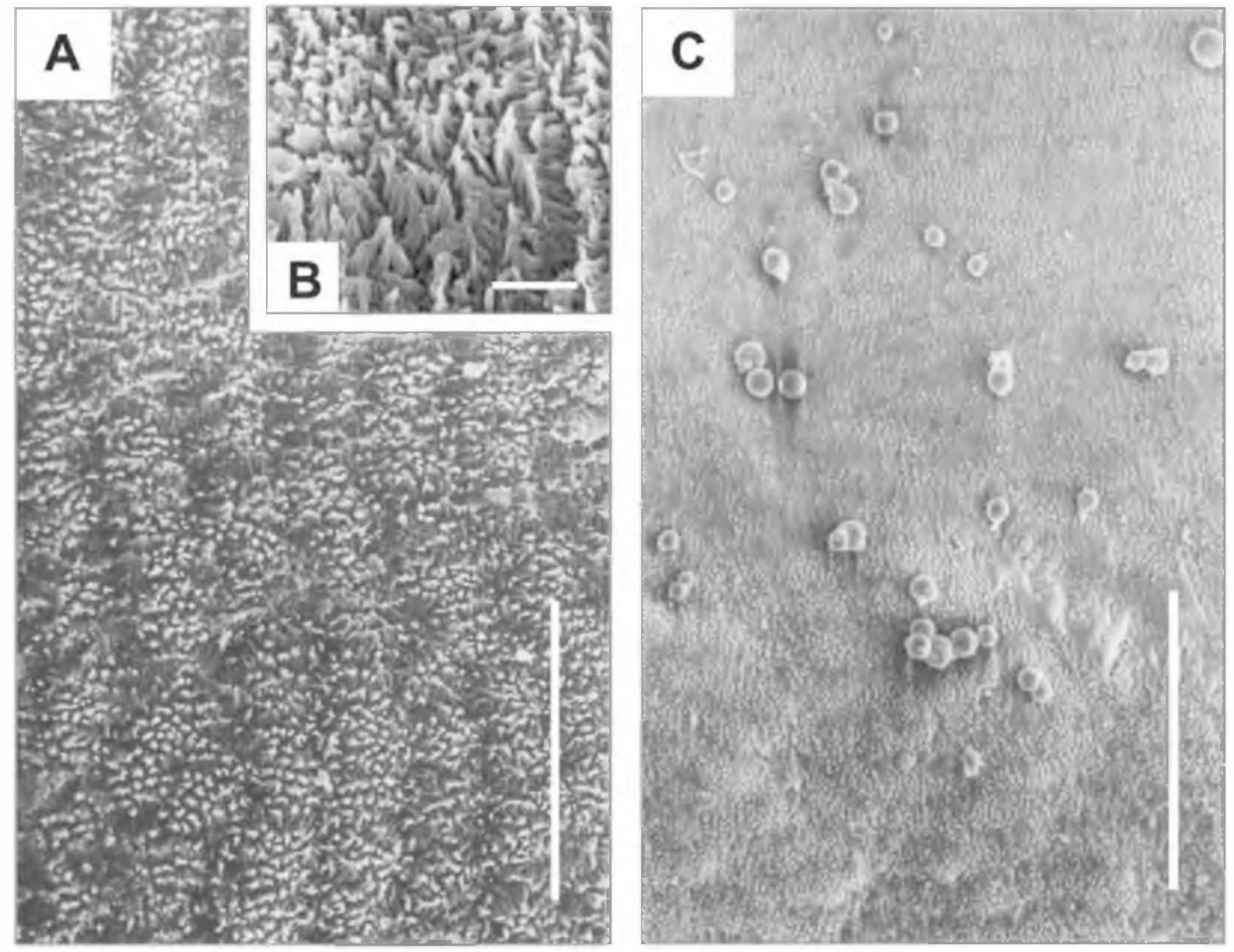

Fig. 1. Paragordius minusculus. A. General view of midbody cuticle. B. Detail of cuticle showing cuticular projections like bristles. C. Midbody cuticle showing rounded structures strange to the holotype. Scale bars $=50 \mu \mathrm{m}(\mathrm{A}), 5 \mu \mathrm{m}(\mathrm{B}), 100 \mu \mathrm{m}$ (C) 
P. minusculus, points out the presence of conic projections and isolated areoles. Our SEM investigations allowed detailed description of the bristle-like projections distributed over the whole cuticle but the areoles mentioned by this author were not observed. It is possible that Carvalho (1944) when observing the cuticle at low optical resolution described those rounded structures scattered over most of the cuticle, which correspond to foreign materials representing contamination of cuticle surface of the holotype. as areoles (see Fig. 1A. B).

\section{Paragordius andreasii sp. nov. (Fig. 2)}

Description: Body light brown, $134 \mathrm{~mm}$ long and $0.8 \mathrm{~mm}$ in diameter. The anterior end rounded with terminal mouth and a dark neck behind the white tip. The posterior end (Fig. 2A) bilobed with 2 lateral lobes $263 \mu \mathrm{m}$ long and $100 \mu \mathrm{m}$ wide. The distance between the bifurcation of the lobes and the cloacal opening $129 \mu \mathrm{m}$. The cloacal opening rounded and devoid of circumcloacal bristles (Fig. 2A). The cuticle around the
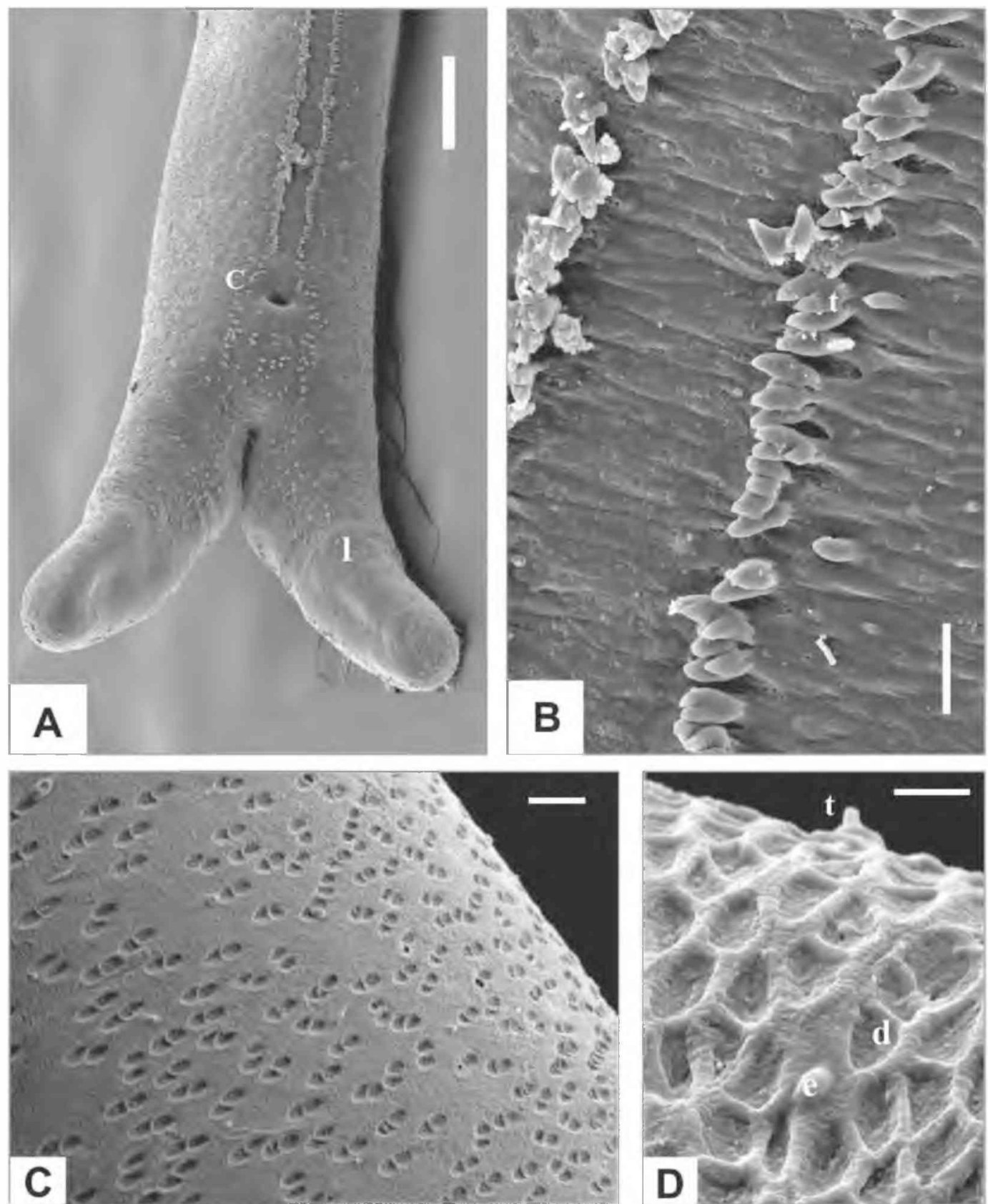

Fig. 2. Paragordius andreasii sp. nov. A. Posterior end: c-cloacal opening; 1 - lobe. B. Ventral furrow with a pair of long rows of tubercles. C. General view of midbody cuticle. D. Detail of lateral view of cuticle: $d$ - depression, e - cuticular elevation, $t-$ tubercle. Scale bars $=100 \mu \mathrm{m}(\mathrm{A}), 10 \mu \mathrm{m}(\mathrm{B}, \mathrm{C}), 5 \mu \mathrm{m}(\mathrm{D})$ 
cloacal opening and in the internal surface of the lobes smooth with sharp conical spines reaching half of the lobes. The rest of the cuticle at the posterior end rough with abundant and small depressions very close to each other (Fig. 2A), being a modification of the cuticular pattern of the midregion of the body. Anterior to the cloacal opening and on both sides of the longitudinal ventral furrow pair of long rows of short single or ramified tubercles (Fig. 2A). The cuticle between the tubercle rows structured by transversal cord-like folds (Fig. 2B).

The midbody cuticle shows oval or rounded depressions (4.1-6.7 $\mu \mathrm{m}$ in diameter), arranged in pairs or forming perpendicular lines to the axis of the body. The space between these depressions is generally wide (between 2.2 and $12.3 \mu \mathrm{m}$ ). with scattered cuticular blunt elevations and tubercles $(3.4 \mu \mathrm{m}$ long) (Fig. 2C. D).

Holotype: Male.

Type locality: Arroyo Piedra Blanca $\left(32^{\circ} 19^{\prime} 00.8^{\prime \prime} \mathrm{S}\right.$. $65^{\circ} 00^{\prime} 18.4^{\prime \prime}$ W) Merlo. San Luis. Argentina.

Host: Unknown.

Material investigated: Holotype (MLP 3573). (SEM posterior end and midbody).

Distribution: San Luis, Merlo, Argentina.

Etymology: The name of this species is dedicated to Dr Andreas Schmidt-Rhaesa that is a great specialist in Nematomorpha.

Remarks: The presence of oval or rounded depressions in the cuticle arranged in pairs or forming perpendicular lines to the axis of the body and generally separated by a wide space is unique and justifies the description of a new species.

\section{Paragordius esavianus Carvalho, 1942 (Fig. 3A)}

Description (holotype female): Body light brown. $211 \mathrm{~mm}$ long and $1 \mathrm{~mm}$ in diameter. Anterior end pointed with a dark ring behind the calotte. The posterior end with three long lobes $(155 \mu \mathrm{m})$. The ultrastructural characteristics of the cuticle (Fig. 3A) are the same as pointed out by de Villalobos et al. (2000) for specimens of this species.

Holotype: Female.

Type locality: Cachoeira do Itapemirim, Estado Espirito Santo, Brazil.

Host: Eidmanacris sp. (Orthoptera. Grylloidea) (new record) (MLP 5037).

Material investigated: Holotype (MNRJ vial 118, without accession number) (stereomicroscope, posterior; SEM midbody); 1 ㅇ (MLP 5037) Cuña Pirú river. Aristóbulo del Valle. Misiones, Argentina.

Distribution: Argentina: Salta: Arenales river, Department Capital (de Villalobos et al. 2000), Escoipe river (de Villalobos et al. 2000); Misiones: Aristóbulo del Valle. Cuña Pirú river (new record). Brazil: Estado Espirito Santo. Cachoeira do Itapemirim (Carvalho 1942).

\section{Paragordius varius (Leidy, 1851) (Fig. 3B)}

Type locality: Philadelphia. U.S.A.

Host: Undetermined Grillydae (MNRJ container 118, vial No. 10) (new record).

Material investigated: $30^{x} 0^{x} .5$ 우 우 (MLP 5043) Córdoba, El Durazno; 1 우 (MLP 5040) Córdoba. Villa Rosas; $1 \sigma^{\top}$ (MLP
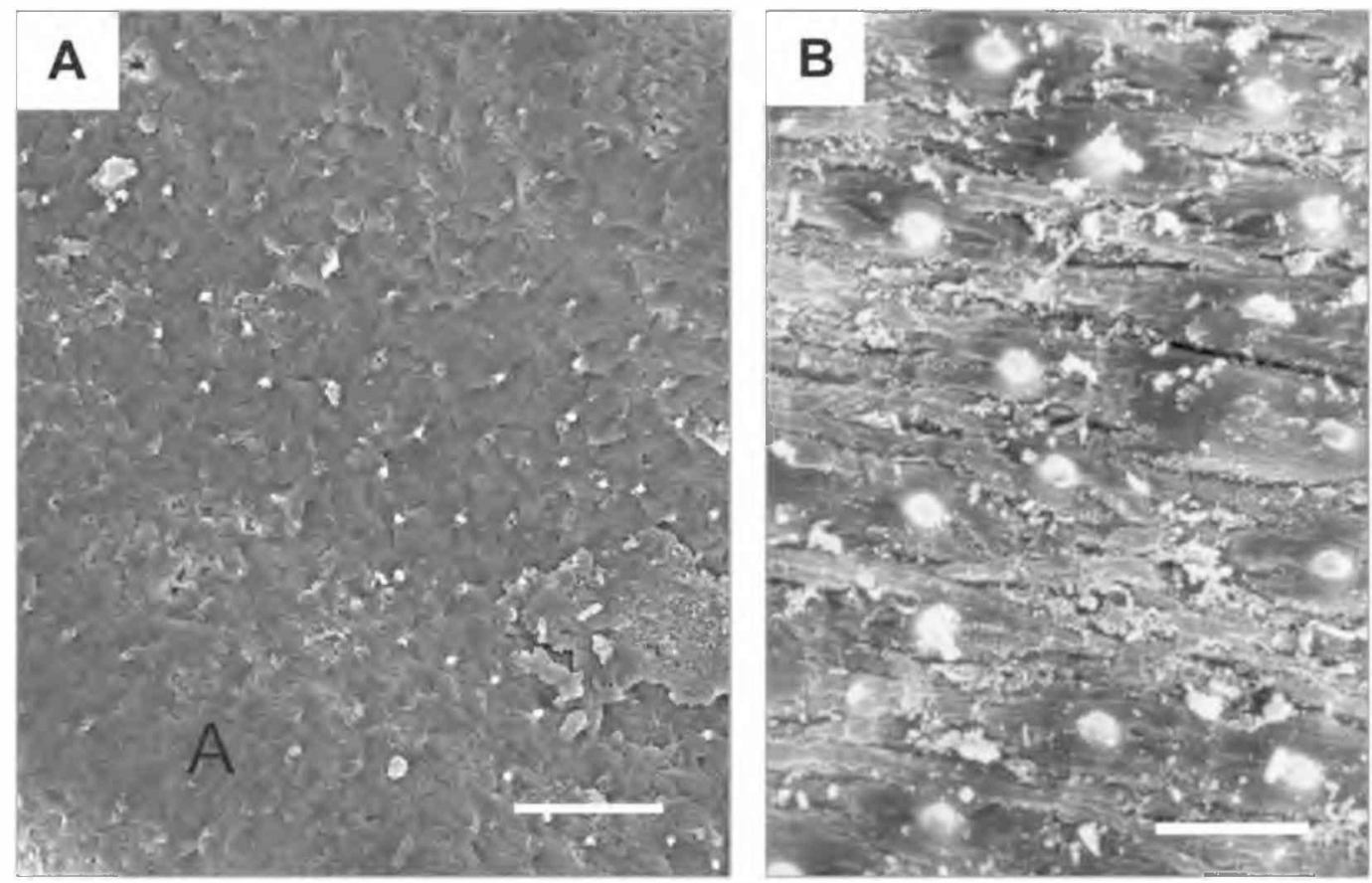

Fig. 3. General view of midbody cuticle. A. Paragordius esavianus holotype. B. Paragordius varius (MLP 5042). Scale bars $=20 \mu \mathrm{m}(\mathrm{A})$, $10 \mu \mathrm{m}(\mathrm{B})$ 
3562). Córdoba. Cabana stream; $1 \sigma^{\top}$ (MLP 3563) Córdoba. Mina Clavero; 1 ㅇ (MLP 3565) Córdoba, Valle Hermoso. Villa Yacouna; $10^{7}$ (MLP 3568) Córdoba. San Antonio river; 1 우 (MLP 3570) Córdoba, Río Primero; 1 우 (MLP 3572) Mendoza. Chacras de Coria; 1 specimen sex unknown (MLP 3569) Mendoza, Los Reyunos; 1 ㅇ (MLP 3571) Mendoza, San Rafael; $10^{x}$ (MACNBR without collection number. 6/47) Misiones. Cerro Azul; 1 ㅇ (MLP 5042) Buenos Aires. Sierra de la Ventana, El Negro stream; $1 \sigma^{x}$ (MLP 5044) Buenos Aires. Sierra de la Ventana, E1 Loro stream; $10^{\top}$ (Museo de San Nicolás, without accession number) Buenos Aires, Ramallo; 2 우 우 (MLP 5042) Río Negro. General Conesa: $10^{x}$ (MLP

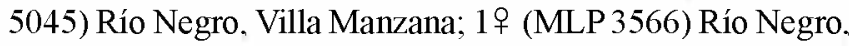
Cipolletti; $10^{1}$ (MLP 3560) Salta. Campo Quijano; 1 ㅇ (MLP 3564) San Luis. Merlo; $1 \sigma^{x} .1$ ㅇ (IML 02441) Tucumán. Burruyacu; $1 \sigma^{\top}$ (IML 01514) Tucumán. Potrero de las Tablas; $1 \sigma^{x}$ (IML 00788) Salta. San Martin department. Campari river; 1 우 (FTyCA no accession number) Tres Puentes. del Valle river; 3 우 우, $10^{x}$ (MNRJ vial 118, No. 10), Minas Gerais, Patos: $10^{x}$ (MNRJ vial 118. No. 29) Rio de Janeiro, Villa Seropédica.

South American distribution: Argentina: Buenos Aires: Ramallo (new record); Sierra de la Ventana: El Loro stream (new record), El Negro stream (new record). Córdoba: (Miralles and de Villalobos 1993), El Durazno (de Villalobos et al. 2000), Villa Rosas (new record), Cabana (new record), Mina Clavero, San Lorenzo stream (new record); Villa Yacouna, Valle Hermoso (new record). San Antonio river (new record). Río Primero (new record). Catamarca: Tres Puentes. Del Valle river (new record). Jujuy: Unspecified location (Miralles 1969). Mendoza: Chacras de Coria (new record). Los Reyunos (new record), San Rafael (new record). Misiones: Cerro Azul (new record). Río Negro: (Miralles and de Villalobos 1993), General Conesa. Villa Manzana (new record), Cipolletti (new record). San Luis: Unspecified location (Miralles and de Villalobos 1993). Merlo (new record). Salta: Unspecified location (Miralles and de Villalobos 1993). Campo Quijano (new record), San Martin department. Campari river (new record). Tucumán: Unspecified location (Miralles 1969), Burruyacu (new record). Potrero de las Tablas (new record). Brazil: Minas Gerais, Patos (new record). Rio de Janeiro, Villa Seropédica (new record)

Remarks: The characteristics of the posterior end and cuticle in males and females are coincident with the redescription carried out by de Villalobos et al. (2000) (see Fig. 3B).

\section{Discussion}

The South American species of Paragordius studied have characteristics of their own at the cuticle level which make them valid species. The cuticle of $P$. minusculus is covered by digit-like cuticular projections producing a velvet-like aspect. In $P$. esavianus the cuticular surface has small cuticular elevations, round tubercles perpendicular to the axis of the body and some long bristles. $P$. varius has irregular areoles with a central tubercle or a central pore, arranged perpendicularly to the axis of the body and cuticular rims between the areoles. In $P$. andreasii sp. nov. oval or rounded depressions are present generally arranged in pairs or forming lines perpendicular to the axis of the body generally separated by a wide furrow. The most widely distributed species of the genus Paragordius is $P$. varius, with registers in Europe (Schmidt-Rhaesa 1997), Central and North America (Schmidt-Rhaesa et al. 2003. Schmidt-Rhaesa and Melzer 2005) and South America (de Villalobos et al. 2000). P. esavianus, P. minusculus and $P$. andreasii sp. nov. is found only in South America. The distribution of $P$. flavescens is doubtful. This species was described by Linstow (1906) from two females, one of them from Tucumán (Argentina) and the other from Costa Rica. Camerano (1915) considers the description as insufficient and assumes an eventual correspondence with $P$. varius and defines it as an "uncertain species". Heinze (1935) studies Linstow's (1906) specimens and finds that the specimen coming from Tucumán coincides with the description of $P$. flavescens and transfers the other specimen to a new species. $P$. diversolobatus. On the other hand. Carvalho (1944) assigns two female specimens from Sâo Paulo (Brazil) to P. flavescens, and Sciacchitano (1958) assigns one female from Kalimbenge, Uvira (Kivu) in the former Belgian Congo (Africa) to P. flavescens. Given that the descriptions are insufficient and the distribution offered by the literature is curious a reinvestigation of all these specimens is necessary in order to establish their real status.

\section{References}

Camerano L. 1895. Gordiens nouveaux ou peu connus de Musée d'Histoire Naturelle de Leyde. Notes Leyden Musée, 17, 1-14.

Camerano L. 1915. Revisione dei gordii. Memorie della R. Accademia delle Scienze di Torino, 46, 1-66.

Carvalho J.C. 1942. Studies on some Gordiacea of North and South America. Journal of Parasitology, 28, 213-222.

Carvalho J.C. 1944. Consideraçōes sỏbre alguns Gordiáceos brasileiris com descrição de duas espécies novas (Gordiacea, Chododidae). Revista Brasileira de Biologia , 4, 485-491.

Heinze K. 1935. Über Gordiiden. Zoologischer Anzeiger, 111, 23-32.

Linstow O. von 1883. Nematoden, Trematoden und Acanthocephalen, gesammelt von Prof. Fedtschenko in Turkestan. Archiv für Naturgeschichte, 49, 274-314.

Linstow O. von 1906. Gordiiden und Mermithiden des Königlichen Zoologischen Museums in Berlin. Mitteilungen aus dem Zoologischen Museum in Berlin, 3, 243-248.

Miralles D. 1969. Lista preliminar de Gordiaceos de Argentina y datos biológicos sobre Neochordodes uniareolatus Carv. Acta Zoologica Lilloana, 24, 183-192.

Miralles D., Villalobos C. de 1993. Gordioidea: Distribución en la Argentina y la Región Neotropical. Fauna de Agua Dulce de la República Argentina, 13, 5-32.

Schmidt-Rhaesa A. 1997. Nematomorpha. In: Süßwasserfauna von Mitteleuropa (Eds. J. Schwoerbel and P. Zwick), Vol. 4/4. Gustav Fischer Verlag, Stuttgart, 1-124.

Schmidt-Rhaesa A. 2002. Are the genera of Nematomorpha monophyletic taxa? Zoologica Scripta, 31, 185-200.

Schmidt-Rhaesa A., Hanelt B., Reeves W. 2003. Redescription and compilation of Nearctic freshwater Nematomorpha (Gordiida), with the description of two new species. Proceedings of the Academy of Natural Sciences of Philadelphia, 153, 77-117. 
Schmidt-Rhaesa A., Menzel L. 2005. Central American and Caribbean species of horsehair worms (Nematomorpha), with the description of three new species. Journal of Natural History, $39,515-529$.

Sciacchitano I. 1958. Gordioidea del Congo Belga. Annales du Musée Royal du Congo Belge Tervuren, 67, 9-111.

Sciacchitano I. 1962 La collezione dei Gordioidei del Museo Civico di Genova. Annali del Museo Civico di Storia Naturale di Genova, LXXIII, 272-281

Villalobos C. de, Ramirez G., Chavarria S., Zanca F. 2000. Cuticular ultrastructure of Paragordius esavianus Carvalho and $P$. varius (Leidy) (Nematomorpha: Chordodidae: Paragordinae).
Proceedings of the Academy of Natural Sciences of Philadelphia, 150, 135-144.

Villalobos C. de, Ribera I., Bilton D. 2001. First data of Iberian Nematomorpha, with redescription of Gordius aquaticus Linnaeus, G. plicatus Heinze, Gordionus wolterstorffii Camerano and Paragordius tricuspidatus (Dufour). Contributions to Zoology, 70, 73-84.

Zanca F., Schmidt-Rhaesa A. 2006. Reinvestigation and new evaluation of representatives from the genera Semigordionus, Euchordodes, Pantachordodes, Dacochordodes and Spinochordodes (Nematomorpha). Mitteilungen aus dem Museum für Naturkunde in Berlin, Zoologische Reihe, 82, 171-179.

(Accepted June 29, 2006) 